on the electroretinogram of normal humans. Retina 1989;9:216-25.

8. Muller W, Haase E. Fragen zur Beeinflussung des Elektrooculogramms durch Diazepam. Graefes Arch Klin Exp Ophthalmol 1975;197:159-64.

9. Malone DA, Camera EG, Krug JH. Ophthalmic effects of psychotropic medications. Psychosomatics 1992; 33:271-7.

10. Elder MJ. Diazepam and its effects on visual fields. Aust NZ J Ophthalmol 1992;20:267-70.

11. Gass JDM. Macular diseases, 3rd ed. St Louis: CV Mosby, 1986;262.

Sir,

\section{Ensuring Graft Centration using a Modified YAG} Laser

Optimal results following penetrating keratoplasty depend on accurate centration of the graft as well as radially positioned sutures of the correct tension. Graft eccentricity is known to cause astigmatism ${ }^{1,2}$ and a clear graft can have poor visual results due to this complication. ${ }^{3}$ A graft which is optically centred correctly and whose border is nearer to the limbus in one meridian may be at a higher risk of rejection. In keratoconus a similarly centred graft whose border has not completely cleared an inferiorly placed cone can result in unexpected astigmatism due to varying wound thicknesses. ${ }^{4}$ Notwithstanding these possible reasons for placing an optical graft eccentrically, the common practice is to aim for accurate centration on the visual axis. Surgical techniques for localising the graft have traditionally involved intraoperative methods, often with the patient under general anaesthetic. The imprint of the trephine can be inspected for concentricity with the pupil, ${ }^{5,6}$ but it can be difficult to be sure the surgeon is not looking obliquely at the pupil centre instead of straight down the visual axis. It has been suggested that miotics may make this task easier ${ }^{6}$ and often these would be used immediately pre-operatively to protect the lens during the operation, but dilation or constriction of the pupil has been found to shift its centre. ${ }^{7}$ The anatomical centre of the recipient cornea can be marked by measuring with calipers ${ }^{8}$ and this may be the only method if the cornea is severely opacified.

Methods used by radial keratotomy surgeons to

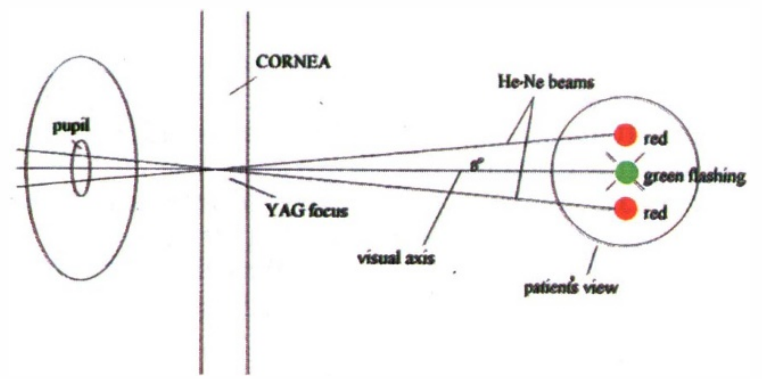

Fig. 1. The aiming beams lie $8^{\circ}$ above and below the $Y A G$ axis and converge at its focus. They are set up to focus on the mid-stroma and pass through the miosed pupil; then the patient is asked to fixate on the flashing green LED. ascertain the centre of the optical zone with the operating microscope are less applicable to graft patients as they require either a good visual acuity in order to fixate a small mark on one of the objective lenses of the microscope while the surgeon marks the corneal epithelium overlying the centre of the entrance pupil (Guyton's method), ${ }^{9}$ or the corneal light reflex is used (often distorted in graft patients) using one or both eyepieces with varying degrees of error according to the magnitude of angle lambda.?

We conducted a pilot study to assess the feasibility of marking the centre of the visual axis on the cornea of three keratoconics about to undergo corneal graft procedures by using a modified Coherent 7970 YAG laser. We asked the patients to look between the two red $\mathrm{He}-\mathrm{Ne}$ aiming beams of the laser $\left(8^{\circ}\right.$ above and below the YAG axis) and focused them in the midstroma enabling the YAG energy to be delivered to the visual axis on the cornea. To help patient fixation and to prevent the patients having to gaze straight at the $\mathrm{He}-\mathrm{Ne}$ beams we positioned a small flashing green light-emitting diode (LED) between the two aiming beams as seen by the patient (Fig. 1). This was attached by a thin cable to a battery unit. It was mounted behind the laser housing, at the front of the microscope unit, and can be fitted without loss of warranty in a matter of minutes simply with a screwdriver. Its installation is simplified by the existence of a suitable hole between the two objective lenses of the microscope, which is fastened to the laser housing using one screw (Fig. 2).

The patients were set up on the chin rest in the normal way but with the other eye occluded. The aiming beams were aligned approximately in the centre of the miosed pupil but focused in the cornea. The patients were then asked to fixate on the green flashing light while confirming the red aiming beams were equidistant above and below. The YAG laser was then fired resulting in an intra-stromal gas

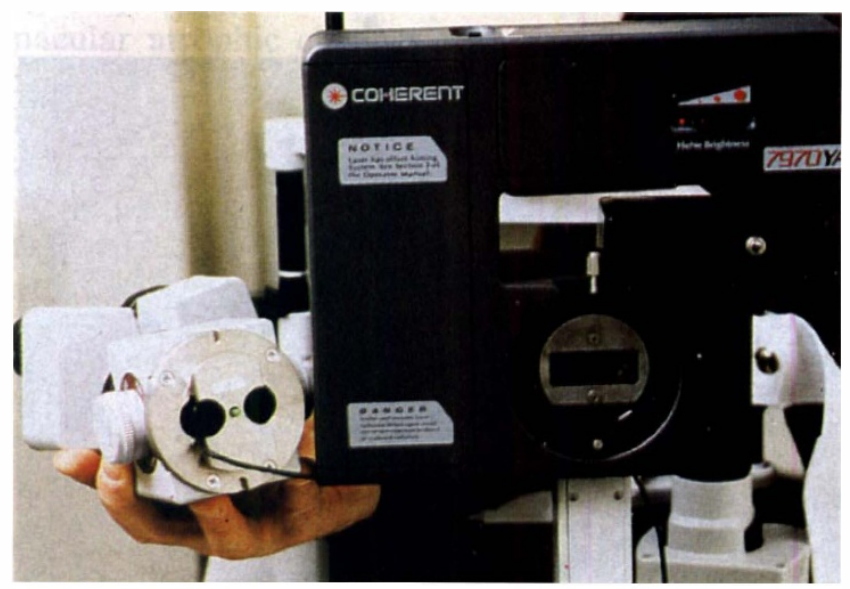

Fig. 2. The microscope optics come away from the main laser body by loosening a screw. The fixation light is fitted in the microscope mounting plate between the objective lenses. 


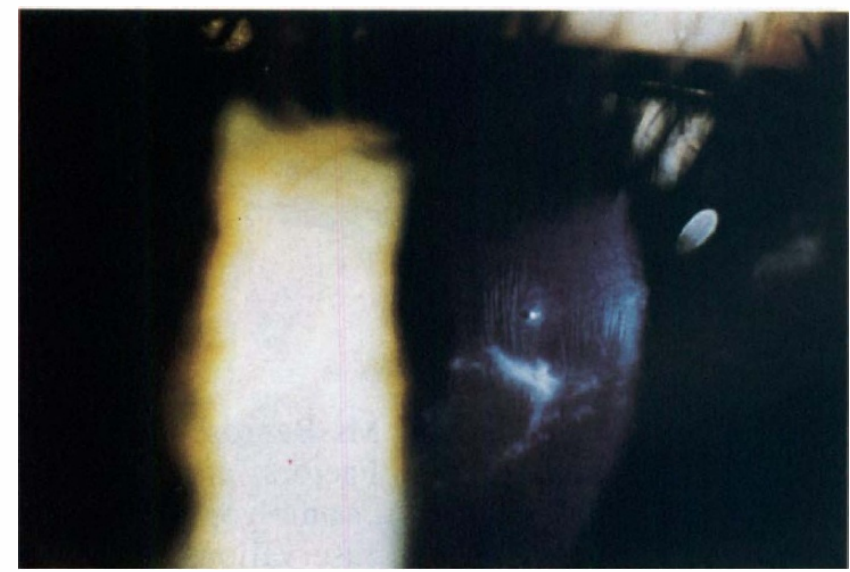

Fig. 3. A slit lamp photograph shows the small gas bubble between the Vogt lines of a keratoconic. Just superior to the mark is an old hydrops scar.

bubble on the patient's visual axis (Fig. 3). The bubble is small but easily visible and was used to centralise a vacuum trephine equipped with crosshairs.

The marking process was performed approximately 4 hours prior to surgery after constriction of the pupil with pilocarpine. Local anaesthetic was used and none of the patients experienced any discomfort. All patients were relatively free of scarring in that they were able to see (albeit blurred) and fixate the light easily, and all admitted to being able to distinguish the centre of the lights from the blurring caused by their astigmatism; however, error could result if visibility of the aiming beams and the fixation light is very poor due to the corneal pathology. These problems may be minimised by having a cooperative patient, a miosed pupil and a minimally scarred cornea. We lasered several pigs corneas and found a YAG energy setting of $1 \mathrm{~mJ}$ produced the required result (a small but well-defined gas bubble). This forms in a few seconds after the initial star-like explosion of gas retracts into a single bubble. However, we found that it remained visible in the cornea for a maximum of 2 hours, which is not long enough to be sure it would still be usable if there was any delay before the trephining procedure. We therefore spotted the YAG mark with Indian ink using a sterile wooden splinter, which was found to function well as a nib. A speculum (taped to the patient's forehead) was used to prevent blinking which may have smudged the ink. The patient was then prepared for surgery. The corneal mark was easily seen through the operating microscope and no problem was encountered in the alignment of the cross-hairs of the vacuum trephine over this mark.

Graft eccentricity is an important cause of visual morbidity yet the methods used for centring grafts can be imprecise. A safe method of reliably and consistently marking the centre of the visual axis on the cornea pre-operatively enables the surgeon to dispense with the procedure of aligning 'by eye' the trephine at the beginning of the operation. This allows him or her to concentrate on the other important factors in graft success such as radial stitches of correct tension and endothelial protection. Our simple modification of an instrument already existing in most departments provides this at very little cost.

P. Mann, FRCOphth

S. Ahmed, FRCOphth

Ninewells Hospital and Medical School Dundee DD1 9SY

UK

\section{Macdonald, FRCS, FRCOphth}

Queen Margaret Hospital

Dunfermline, Fife

UK

\section{References}

1. Rij G, Cornell FM, Waring GO III, Wilson LA, Beekhuis WH. Postoperative astigmatism after central vs eccentric penetrating keratoplasties. Am J Ophthalmol 1985;99:317-20.

2. Casey TA, Mayer DJ. Grafting for beginners. In: Corneal grafting: principles and practice. Philadelphia: WB Saunders, 1984:157-62.

3. Casey TA, Mayer DJ. Complications of grafting. In: Corneal grafting: principles and practice. Philadelphia: WB Saunders, 1984:289-308.

4. Casey TA, Mayer DJ. Keratoconus. In: Corneal grafting: principles and practice. Philadelphia: WB Saunders, 1984:163-70.

5. Steele AD, Kirkness CM. Routine penetrating keratoplasty. In: Manual of systemic corneal surgery. Edinburgh: Churchill Livingstone, 1992:25-9.

6. Steele AD, Kirkness CM. Corneal surgery. In: Willshaw $\mathrm{H}$, editor. Practical ophthalmic surgery. Edinburgh: Churchill Livingstone, 1992:1-27.

7. Uozato H, Guyton DL. Centering corneal surgical procedures. Am J Ophthalmol 1987;103:264-75.

8. Lanier JD. Basic surgical principles of penetrating keratoplasty. Refract Corneal Surg 1991;7:92-8.

9. Hersh P. Radial keratotomy. In: Ophthalmic surgical procedures. Boston: Little, Brown, 1988:241-6. 